\title{
ESCRAVIDÃO CONTEMPORÂNEA: Uma Análise do Caso do Trabalho Análogo ao de Escravo no Estado do Amazonas
}

\author{
http://dx.doi.org/10.21527/2176-6622.2021.55.41-48
}

Recebido em: 30/4/2020

Modificações solicitadas em: 26/6/2020

Aceito em: 21/7/2020

Brychtn Ribeiro de Vasconcelos

Autor correspondente. Universidade do Estado do Amazonas. http://lattes.cnpq.br/0445762148028931. https://orcid.org/0000-0002-8567-8499. brychtn@gmail.com

Daphine Ramiro Herrera

Departamento de Ciências Biológicas da Unesp. Bauru/SP, Brasil.

\section{RESUMO}

O combate ao trabalho escravo no Brasil passou a ter expressão a partir da alteração do Código Penal brasileiro e por meio da Constituição Federal. Atualmente, a escravidão contemporânea apresenta-se como violação da dignidade humana, dos valores sociais do trabalho e da liberdade e, apesar das leis e intervenções existentes, o trabalho análogo à escravidão persiste, todavia, sob novas formas, sendo um problema que necessita ser analisado a fim de responder essa contingência. Este artigo trata da análise do caso do trabalho análogo ao de escravo no Estado do Amazonas, no município de Barcelos, em 2014. Baseado no método dedutivo, pautado na análise documental, conclui-se que o resgate de 13 trabalhadores em condições análogas à de escravo demonstra a importância de fiscalização e participação dos órgãos públicos. Para, porém, o combate ao trabalho análogo ao de escravo, é necessário a regulamentação da atividade extrativista e a eliminação do aviamento e políticas públicas educacionais em conjunto com leis precisas e fiscalização eficaz.

Palavras-chave: Trabalho escravo. Dignidade da pessoa humana. Trabalhadores resgatados. Políticas públicas.

\section{CONTEMPORARY SLAVERY: AN ANALYSIS OF THE CASE OF LABOR ANALOGOUS TO THAT OF SLAVE IN THE STATE OF AMAZONAS}

\section{ABSTRACT}

The action against slave labor in Brazil has come to be expressed through the amendment of the Brazilian Penal Code and the Federal Constitution. Currently, contemporary slavery presents itself as a violation of human dignity, the social values of work and freedom and, despite existing laws and interventions, work analogous to slavery persists, however, in new forms, being a problem that needs to be analyzed in order to answer this contingency. This paper analyses the case of work analogous to slavery in the State of Amazonas, in the municipality of Barcelos in 2014. Based on the deductive method, on documentary analysis, it is concluded that the rescue of 13 workers in conditions analogous to slave labor, demonstrates the importance of inspection and participation by public agencies. However, in order to combat the work analogous to slavery, it is necessary to regulate extractive activities, eliminate the aviation and educational public policies in conjunction with precise laws and effective inspection.

Keywords: Slave labor. Dignity of the human person. Rescued workers. Public policy.

\section{SUMÁRIO}

1 Introdução. 2 A história da escravidão no Brasil. 3 Escravidão contemporânea. 4 Condições análogas ao trabalho escravo na Região Norte no Estado do Amazonas. 5 Propostas de soluções para os desafios enfrentados. 6 Conclusões. 7 Referências. 


\section{INTRODUÇÃO}

No Brasil, apesar de a escravidão ter sido abolida há 131 anos por meio da promulgação da Lei Áurea, ainda hoje é notória a presença de um grande número de trabalhadores escravizados, sob novas formas de sujeição do indivíduo, nas diversas regiões do país, o que contrapõe a convicção institucionalizada de que a interdição normativa basta para encerrar o fenômeno.

O Código Penal brasileiro e a Constituição Federal de 1998 incriminam qualquer conduta de reduzir alguém à condição análoga à de escravo, com base no princípio da dignidade da pessoa humana. Ainda assim, historicamente, o Estado brasileiro desempenhou diferentes papéis quanto ao trabalho escravo, legitimando-o em alguns momentos e criminalizando-o em outros.

O trabalho escravo apresenta-se como uma violação aos direitos humanos renitente no Brasil. Paralelamente, existe, há mais de duas décadas, um sistema de combate ao trabalho escravo sendo introduzido pelo Estado brasileiro, que deriva de um conjunto de políticas públicas que tem enfatizado as ações de repressão ao trabalho escravo por meio das fiscalizações e do resgate de trabalhadores (SUZUKI, 2017).

No início de 2014 uma operação conjunta entre Ministério Público do Trabalho (MPT) e o Ministério Público Federal no Amazonas (MPF-AM) resgatou 13 trabalhadores em condições análogas à de escravo no Amazonas, Região Norte do país. Essa notícia, entre outras, mostra que o trabalho escravo é ainda uma realidade e um problema que merece atenção.

Assim, embora a escravidão tenha sido abolida e institucionalizada, as práticas atuais que submetem os trabalhadores a condições degradantes e exaustivas de trabalho, tendo a liberdade restringida, apresentam-se como uma nova forma de escravidão contemporânea e uma problemática, marcada pela desigualdade endêmica de sua estrutura, que necessita ser analisada a fim de responder a essa contingência.

Diante das constantes operações e notícias sobre essa temática, estudos que visam a compreender as bases do trabalho escravo contemporâneo são de importância crescente, pois apresentam reflexos em toda a estrutura social, impactando nas relações jurídicas e no posicionamento e atuação dos órgãos responsáveis pelo combate e fiscalização dessa prática.

Sendo assim, o presente artigo tem por objetivo analisar as características do trabalho análogo ao de escravo, focando especificamente no estudo de caso do trabalho escravo registrado no Estado do Amazonas, no município de Barcelos, e a violação aos fundamentos constitucionalmente protegidos, apresentando os aspectos que evidenciam a sua concretização.

O procedimento metodológico trabalhado foi o método dedutivo e o discurso do tipo expositivo-argumentativo, uma vez que foram analisados materiais pesquisados a partir de uma revisão de literatura e da legislação em vigor no que se refere às formas análogas à de escravidão. A elaboração foi quanto ao tipo básico e documental por meio da atualização e da investigação do conhecimento da pesquisa.

A estratégia metodológica utilizada para mapear a estrutura do conhecimento sobre a escravidão no Brasil ocorreu por análise quali-quantitativa, e foram compiladas a partir de conclusões dos artigos, textos e dados.

\section{A HISTÓRIA DA ESCRAVIDÃO NO BRASIL}

O Brasil Colônia tinha como sentido econômico exclusivamente a exportação. Consequentemente, não houve o desenvolvimento de um mercado interno com necessidade de existência de trabalhadores assalariados para consumir tal produção. Surge, assim, a necessidade de trabalho compulsório para atender ao próprio sentido da colonização, e o escravismo adquire a natureza de modo de produção dominante (SILVA; BOAVENTURA, 2014).

No início lograram atrair tribos indígenas a colaborar na obra da colonização, engajando-os como trabaIhadores nas fazendas e engenhos. Os processos brutais empregados pelos portugueses para forçar os indígenas ao trabalho, porém, não os atraiam, forçando-os a fugas e confrontos constantes (PRADO JR., 2012). 
A escravidão indígena manteve-se até meados do século 18 , quando foi totalmente abolida, seja pela baixa densidade demográfica da população, pela dizimação provocada pelas doenças ou pela evasão dos indígenas, e substituída apenas pelos escravos africanos que se constituía em atividade extremamente lucrativa (PRADO JR., 2012; MIRAGLIA, 2015).

Ao percorrer a costa africana no século 15 , os portugueses já haviam começado o tráfico de africanos, facilitado por sociedades que conheciam o valor mercantil do escravo. Os cálculos sobre o número de pessoas transportadas como escravos para o Brasil variam muito, mas estimativas mostram que entre 1550 e 1855 entraram pelos portos brasileiros cerca de 4 milhões de escravos (FAUSTO, 2012).

Os grandes centros importadores de escravos no Brasil foram Salvador, que utilizava o fumo produzido no Recôncavo como moeda de troca, e o Rio de Janeiro, superando a Bahia com a descoberta das minas de ouro, o avanço da economia açucareira e o grande crescimento urbano da capital a partir do início do século 19 (FAUSTO, 2012).

A estrutura social da colônia era extremamente simples no primeiro século e meio da colonização. De um lado os proprietários rurais, senhores de engenho e fazendas; do outro a população dos trabalhadores do campo, os escravos, ou seja, toda a população vive na dependência dos senhores rurais (PRADO JR., 2012).

$\mathrm{Na}$ ordem política, até meados do século 17 a autoridade era exercida dentro dos limites da sede do governo-geral, representando, assim, a fixação de um polo administrativo na organização da Colônia (FAUSTO, 2012), e as massas populares eram mantidas numa sujeição completa por diplomas normativos vigentes e instituições opressivas que legitimavam a escravidão.

Em 1830 a Inglaterra propôs um tratado com o intuito de extinguir a entrada de novos escravos no território brasileiro, declarando livres os escravos que entrassem no Brasil após 1831, e prevendo aplicações severas aos traficantes de escravos. Somente em 1850, porém, inicia-se a abolição ao tráfico de escravos no Brasil (OLIVEIRA, 2017).

A Lei do Ventre livre foi aprovada em 1871, declarando livres os filhos da mulher escrava que nascessem a partir daquele ano e, em 1885, a Lei dos Sexagenários libertava os escravos que chegassem aos 60 anos de vida (BRASIL, 2017).

A Lei no 3.353, conhecida como Lei Áurea, foi promulgada em 1888, declarando extinta a escravidão no Brasil. De acordo com Oliveira (2017), a Lei Áurea é considerada um marco definitivo após anos de luta, em processo de abolição lento e gradual, que aprovou leis que pouco valeram.

\section{ESCRAVIDÃO CONTEMPORÂNEA}

Com o passar do tempo a escravidão adquiriu distintos conceitos e nomenclaturas. Após 131 anos, os sistemas de produção e os modos de contratação mudaram, assim como as formas de exploração do trabalho humano, a legislação e a própria escravidão (LACERDA; TOSTES; CANTELLI, 2018).

O termo "escravidão" é tradicionalmente compreendido como a submissão de um indivíduo a outro. De acordo com Cerqueira (2017), a Convenção de Genebra, de 1926, define escravidão como "estado ou condição de um indivíduo sobre o qual se exercem, total ou parcialmente, os atributos do direito de propriedade". Essa definição remete-nos ao período colonial, porém persiste atualmente a escravidão mediante métodos de coação mais complexos que precisam ser cuidadosamente examinados.

O combate ao trabalho escravo no Brasil passou a ter expressão a partir da edição da Lei no 10.803, de 2003, que alterou profundamente o artigo 149 do Código Penal brasileiro, tipificando como crime de reclusão de dois a oito anos submeter alguém a trabalhos forçados, jornadas exaustivas, condições degradantes e liberdade restringida por terem contraído dívida junto a seus empregadores (BRITO FILHO, 2012).

O Código Penal trouxe, de fato, condutas aptas a caracterizar o ilícito penal do trabalho escravo, porém são as normas internacionais sobre direitos humanos e a Constituição Federal, ao dispor sobre dignidade da pessoa humana e valores sociais do trabalho (artigo $1^{\circ}$ ), que dão conteúdo jurídico à tipificação do crime (MIRAGLIA; SOUZA; CHAVES JR., 2018).

Atualmente, a escravidão contemporânea pode ser tratada como escravidão branca, que, por sua vez, é utilizada no sentindo de demonstrar que a exploração do trabalho escravo contemporâneo não leva em conta a raça ou a cor do trabalhador (BELISÁRIO, 2005), ou, também, trabalho em condições análogas à de escravo, 
expressão que se encontra em sintonia com o disposto no artigo 149 do Código Penal, igualmente denominado pela doutrina de plágio, que consiste em reduzir alguém à condição análoga à de escravo (MIRABETE, 2005).

Seja como for, independentemente da terminologia utilizada, observa-se que o ponto comum das distintas formas de apresentação do trabalho em condições análogas à de escravo é a violação à dignidade do trabalhador (LACERDA; TOSTES; CANTELLI, 2018).

Apesar das leis e intervenções de combate ao trabalho em condição análoga à escravidão, dados coletados pela Organização Internacional do Trabalho (OIT), de 2019, estimam que 40 milhões de pessoas são submetidas a regimes de trabalho forçado no mundo. De acordo com Miraglia (2015), o Brasil convive, hoje em dia, com cerca de 40 mil indivíduos sujeitos ao trabalho em condição análoga ao de escravo.

Desse modo, é fundamental que a análise do trabalho escravo concreto seja feita à luz da dignidade humana. O Direito do Trabalho deve conceituar o trabalho em situação análoga à de escravo, de modo a abarcar todo aquele trabalho que desrespeite a dignidade da pessoa humana (LACERDA; TOSTES; CANTELLI, 2018).

\section{CONDIÇÕES ANÁLOGAS AO TRABALHO ESCRAVO NA REGIÃO NORTE NO ESTADO DO AMAZONAS}

De acordo com Miraglia (2015), a escravidão contemporânea faz, historicamente, suas vítimas no meio rural principalmente nas atividades de pecuária, agricultura, desmatamento, extrativismo e produção de carvão. Apesar de todos os esforços realizados nas últimas duas décadas, a exploração ilícita da mão de obra de trabalhadores permanece como um problema social grave no país.

No Estado do Amazonas, entre 2008 e 2014, foram resgatados 376 trabalhadores em condições análogas à de escravo. Em 2014, foram realizadas duas ações fiscais que resultaram no resgate de trabalhadores na região do alto e médio Rio Negro, nos municípios de Santa Isabel e Barcelos, envolvendo a extração da palmeira piaçava (Leopoldinia piassaba) (CPT, 2015).

No município de Barcelos, a 405 quilômetros de Manaus, uma operação conjunta entre o Ministério Público do Trabalho (MPT) e o Ministério Público Federal no Amazonas (MPF-AM) resgatou 13 trabalhadores em condições análogas à de escravo.

Segundo os dados do MPT (2014), o grupo trabalhava na extração de piaçava - fibra largamente utilizada na confecção de vassouras. Os trabalhadores eram submetidos a jornadas excessivas de trabalho e ao aviamento - servidão por dívida - ou seja, os trabalhadores eram impelidos por intermediários, chamados de "patrõezinhos" ou "aviadores", a contrair dívidas com o empregador antes de iniciar a atividade, a partir de adiantamentos em dinheiro ou insumos, com valores superfaturados em até $140 \%$.

De acordo com a Procuradoria da República no Amazonas, as dívidas surgidas desses adiantamentos costumam consumir quase toda - quando não toda ou ser mesmo superior a ela - a remuneração devida aos piaçaveiros. Estabelece-se, assim, um ciclo de repressão da forma de trabalho por meio da dívida e outros mecanismos de dominação.

O regime de aviamento é proibido pela legislação brasileira, em normas como a Consolidação das Leis do Trabalho (CLT) e o Código Penal. De acordo com a CLT, o empregador é vetado de efetuar qualquer desconto nos salários dos empregados, salvo ressalvas, exercendo coação no sentido que os empregados utilizem serviços de venda de mercadorias da empresa visando o lucro ou benefício para esta. Já o Código Penal veda restringir, por qualquer meio, a locomoção em razão de dívida contraída com o empregador.

Segundo a Procuradoria da República no Amazonas (Pram), o relatório da fiscalização realizada em Barcelos descreve que os alojamentos eram construções improvisadas no interior da Floresta Amazônica, sem condições básicas de subsistência, segurança e higiene. Desta forma, 11 trabalhadores pernoitavam em barracos improvisados, um dormia num casebre de madeira e dois pernoitavam em pequenas embarcações atracadas nos igarapés próximos às frentes de trabalho (PRAM, 2014).

A água consumida era captada por eles mesmos no rio ou nos igarapés, sujeita a contaminações, e não havia energia elétrica em nenhum desses locais. A rotina de trabalho consistia na extração das fibras da piaçava de segunda a sexta-feira e os sábados e domingos eram reservados apenas para o beneficiamento do produto, penteando e amarrando a piaçava (PRAM, 2014). 
Ainda de acordo com o relatório, para evitar provas de crime o empresário do ramo de piaçava omitiu, em documentos de Previdência Social, o nome dos trabalhadores, seus dados pessoais, a vigência do contrato de trabalho ou de prestação de serviços e sua remuneração (PRAM, 2014).

Do inquérito do MPF resultam dois processos na Justiça Federal (esferas penal e cível), e do inquérito do MPT resultou um processo na Justiça do Trabalho (esfera trabalhista).

Na denúncia, Processo 0016064-35.2014.4.01.3200 - 4a Vara da Justiça Federal -, o MPF-AM pede à Justiça Federal a condenação do empresário pelos crimes de redução à condição análoga à de escravo, previsto no artigo 149 do Código Penal, de frustração de direito assegurado por lei trabalhista, constante do artigo 203 do Código Penal, e de falsificação de documento público, relativo ao artigo 297 do Código Penal (BRASIL, 2014).

Este processo encontra-se no status "em movimentação" em consulta virtual. Na sua última sentença, o réu foi absolvido em primeira instância no que se refere ao artigo 149, depois de constatado não haver indícios de tal crime conforme apontado a partir de depoimentos de testemunhas; os demais foram encaminhados à Justiça Estadual.

No processo 0014847-20.2015.4.01.3200 - 3a Vara da Justiça Federal - a empresa e o proprietário foram processados pelo MPF-AM a reparar o dano moral coletivo sofrido pelos povos tradicionais da região, ficando proibidos de comercializar as fibras de piaçava sobre regime de aviamento, devendo formular pedido de desculpas à comunidade local bem como financiar material didático sobre trabalho escravo contemporâneo. Os bens da empresa foram bloqueados até o limite de $\mathrm{R} \$ 500.000,00$ pela Justiça (BRASIL, 2015).

Em ação civil pública, Processo 607-55.2014.5.11.401 - 11a Região do Tribunal Regional do Trabalho -, - MPT busca a reparação pelos danos causados pela empresa e pretende garantir o pagamento das verbas rescisórias e indenizações dos trabalhadores resgatados (BRASIL, 2019).

O processo requer, ainda, que a empresa seja condenada a cumprir 26 obrigações, que se circunscreviam enquanto regras básicas trabalhistas, que poderiam assegurar o respeito ao princípio da dignidade humana. Atualmente, este processo está tramitando ainda em "grau de recurso", ou seja, o processo foi para uma instância superior ( 2 a instância) para confirmar ou não a sentença já proferida, posto que houve recurso por parte do réu.

A partir da decisão limiar, e já no processo 0008134-89.2016.4.01.0000, outra sentença é dada: a empresa e seu proprietário têm obrigação de não fazer, consistente em abstenção quanto à exploração do trabaIho e à comercialização de piaçava baseados no regime de aviamento, deixando de promover qualquer tipo de adiantamento ou relação não regularizada com os trabalhadores, tampouco cobrança quanto a supostas dívidas pretéritas baseadas naquela relação.

A ação prevê, ainda, que os requeridos formulem pedido de desculpas, nos autos do processo, direcionado aos povos tradicionais da região onde houve exploração ilegal do trabalho sob regime de aviamento, com ampla publicidade no meio radiofônico durante um mês.

Diante disso, com o trânsito em julgado do processo, as constrições existentes sobre os bens dos requeridos foram retiradas, bem como devolvidos os valores bloqueados com base no artigo 18 da Lei no 7.347/1985. Essa nova sentença absolve o mesmo réu na ação penal do crime de redução à condição análoga à de escravo (Processo 0016064-35.2014.4.01.3200).

\section{PROPOSTAS DE SOLUÇÕES PARA OS DESAFIOS ENFRENTADOS}

A partir das análises históricas, legislativas e do estudo do caso sobre o trabalho análogo à escravidão no Brasil e, em especial na região do Rio Negro no Amazonas, faz-se necessário examinar os desafios observados no combate ao trabalho análogo à escravidão.

De acordo com a Constituição Federal de 1988, a dignidade da pessoa humana e os valores sociais do trabalho e da livre-iniciativa são fundamentos do Estado brasileiro, atributos que todo ser humano possui independente de sua origem, raça, sexo, cor ou condição social. O princípio constitucional da dignidade humana, portanto, assegura um tratamento humano e não degradante e garante o respeito à integridade física, psíquica e moral do ser humano (DUSEK, 2015). 
De acordo com Sarlet (2015), a dignidade da pessoa humana é uma qualidade intrínseca e distintiva reconhecida em cada ser humano, implicando um complexo de direitos e deveres fundamentais que assegure a pessoa contra todo e qualquer ato de cunho degradante e desumano e lhe garanta as condições existenciais mínimas para a vida saudável.

A redução à condição análoga à de escravo fica caracterizada também quando há restrição, por qualquer meio, da liberdade de locomoção, como em razão de servidão por dívida e retenção de documentos (HADDAD, 2013). O direito à vida, à liberdade, à igualdade, à segurança e à propriedade, é um fundamento garantido a todos, sem distinção de qualquer natureza pela Constituição Federal.

Quando existe a prática do trabalho análogo ao de escravo, como meio para atingir um fim, como mão de obra barata, com ideia de superproduzir e de obter superlucro, estando estes trabalhadores desprovidos de condições mínimas de segurança, higiene, sobrevivência e locomoção, há a violação tanto da dignidade da pessoa humana quanto dos valores sociais do trabalho e da liberdade.

Com isso, a lesão desses fundamentos ocorre quando trabalhadores são submetidos ao regime de aviamento, sem poder ir e vir, alojados sem condições de subsistência, alimentação precária, jornadas árduas de trabalho e omissão dos direitos trabalhista, como visto no caso dos piaçaveiros em Barcelos, no Amazonas.

Zuardi, Ramos-Filho e Bentes (2019) sugerem que se estabeleça uma definição de trabalho análogo à escravidão no Brasil que inclua todas as formas dessa prática, além do fortalecimento da legislação, da fiscalização e do combate do trabalho análogo à escravidão.

Um dos desafios enfrentados pelo Brasil consiste na definição de trabalho análogo à escravidão. Apesar de todos os instrumentos citados até aqui, em 2017 o Ministério do Trabalho publicou a Portaria no 1.129, que alterava os conceitos que devem ser usados pelos fiscais para identificar trabalho forçado, jornada exaustiva e condições análogas à escravidão para fins de concessão de seguro-desemprego ao trabalhador resgatado em fiscalização, bem como o modo como é feita a inclusão de empresas na chamada "lista suja", que engloba aqueles que desrespeitam os direitos trabalhistas.

Segundo a Organização Internacional do Trabalho (OIT), a medida muda o conceito dessa violação e pode causar o aumento da desproteção e da vulnerabilidade dos trabalhadores, pois coloca em risco o cumprimento dos Objetivos de Desenvolvimento Sustentável da ONU (ODS) (LAPORTA, 2017).

O país precisa combinar de modo a conciliar todas as relações aos instrumentos já estabelecidos quanto à definição do trabalho análogo à escravidão e caminhar no sentido de complementá-los por outros que tenham o objetivo de trazer mais proteção aos trabalhadores, levando em conta o estado ou condição do indivíduo e o exercício de algum atributo do direito à liberdade individual como fundamentos principais.

Para enfrentar esse cenário é fundamental haver legislação precisa e fiscalização eficaz para enfrentar o trabalho escravo, combatê-lo por meio de penas impostas aos empregadores e, principalmente, viabilizar a atividade extrativista. De acordo com Haddad (2013), a eliminação do trabalho escravo nas fazendas depende da superação da estrutura agrária desigual caracterizada por relações sociais de dominação e poder.

Medidas efetivas devem ser tomadas pelo Poder Público com o compromisso no sentido de regularizar a cadeia produtiva da piaçava e acabar com o regime de aviamento na atividade extrativista do Estado do Amazonas e em outras regiões do Brasil, por meio do fortalecimento da atividade econômica para a redução do desemprego e dos trabalhos informais.

Além disso, não bastam ações pontuais de fiscalização; é necessário um conjunto de medidas de valorização e reparação dos trabalhadores e dos espaços de trabalho, dando condições para o desenvolvimento autônomo de suas relações sociais, bem como o acesso às políticas públicas.

De acordo com Zuardi, Ramos-Filho e Bentes (2019), uma boa solução para prevenir que pessoas em vulnerabilidade sejam vítimas do trabalho escravo é investir em medidas de capacitação profissional em áreas carentes e uma rede de atendimento para as vítimas de tal prática.

Ações que levem a políticas públicas educacionais específicas são essenciais neste contexto, formando cidadãos ativos e aptos a participarem da vida social. Medeiros (2008) interliga a educação e o trabalho como soluções para o desenvolvimento individual e social, pois a qualificação melhora a condição de alta vulnerabilidade e agrega valor à atividade desenvolvida pelos trabalhadores. 
Um exemplo de política pública educacional é o Plano Nacional de Qualificação (PNQ), criado a partir de 2003 para ações de qualificação social e profissional, integrado por vários planos regionalizados, com parceria de todas as esferas do governo e iniciativa privada, atendendo às demandas por qualificação com base na territorialidade, levando em consideração as peculiaridades de cada região (PENHA, 2016).

Neste sentido, é imprescindível que se regularize as atividades extrativistas e a reforma agrária e se desenvolva ações permanentes de educação e qualificação dos piaçaveiros, inclusive mediante ações de conscientização quanto às relações de trabalho na atividade extrativista e políticas de reinserção social, de forma a assegurar que os trabalhadores resgatados não voltem a condições análogas à escravidão novamente.

\section{CONCLUSÃO}

Entender as raízes e a evolução dos conceitos do trabalho análogo ao de escravo no Brasil é de extrema importância para o fortalecimento do combate à escravidão contemporânea. Nota-se que apenas uma legislação precisa não é suficiente para abolirmos o trabalho escravo, pois não se trata apenas de um problema jurídico com questão penal. É preciso que haja o fortalecimento ao combate por meio de uma fiscalização eficaz, da regulamentação da atividade e de políticas públicas educacionais específicas para cada região.

O caso da extração da piaçava no Estado do Amazonas em 2014 e o resgate dos 13 trabalhadores em condições análogas à de escravo, ocorreu por meio de ação conjunta de fiscalização entre o Ministério Público do Trabalho e o Ministério Público Federal, demonstrando fundamental participação dos órgãos envolvidos, gerando três processos nas esferas penal, cível e trabalhista, aos quais responde o mesmo réu, sendo condenado na Justiça do Trabalho.

Dentre os desafios apresentados ao combate do trabalho análogo à escravidão, está a ausência de uma definição e caracterização do problema, sendo necessário conciliar os instrumentos já estabelecidos e caminhar no sentido de complementação e proteção dos trabalhadores; melhorar a fiscalização do trabalho e a aplicação de penas aos infratores; e investir em políticas públicas educativas destinadas à qualificação dos trabalhadores, assegurando-se, assim, o exercício da cidadania.

Deste modo, é possível constatar que a regulamentação da atividade, a eliminação do aviamento e a educação, são pontos centrais encarados sob os enfoques sociais, jurídicos e econômicos, para tentar reduzir o trabalho análogo ao de escravo no extrativismo.

Ações que levem a uma conscientização política, conhecimento sobre os direitos e deveres básicos do cidadão e capacitação dos trabalhadores para o desenvolvimento autônomo de suas relações, serão a chave para enfrentar séculos de imobilização da força de trabalho.

\section{REFERÊNCIAS}

BELISÁRIO, Luiz Guilherme. A redução de trabalhadores rurais a condições análoga à de escravo: um problema de direito penal trabalhista. São Paulo: LTR. 2005.

BRASIL. Ministério Público Federal. Escravidão contemporânea. 2a Câmara de Coordenação e Revisão Criminal. Brasília: MPF, 2017.

BRASIL. Justiça Federal (4a Vara). Apelação criminal. Processo no 0016064-35.2014.4.01.3200. Relator: Ney Bello. Brasília, 21 nov. 2014.

BRASIL. Justiça Federal (3a Vara). Apelação Criminal. Processo no 0014847-20.2015.4.01.3200. Relator: João Batista Moreira. 13 out. 2015.

BRASIL. Tribunal Regional do Trabalho (11a Região). Ação Civil Pública. Processo no 0000607-55.2014.5.11.0401. Relator: Sandro Nahmias Melo. Presidente Figueiredo, 31 jul. 2019.

BRITO FILHO, José Claudio Monteiro. Dignidade da pessoa humana como fundamento para o combate ao trabalho em condições análogas à de escravo: a contribuição da 1a turma do Tribunal Superior do Trabalho no processo TST-RR-178000-13.2003.5.08.0117. Revista do Tribunal Superior do Trabalho, Brasília, v. 78, n. 3, p. 93-107, 2012.

CERQUEIRA, Diego Barbato. Um estudo introdutório sobre a escravidão contemporânea. In: BRASIL. Ministério Público Federal. Escravidão contemporânea. 2a Câmara de Coordenação e Revisão Criminal. Brasília: MPF, 2017.

CPT. Comissão Pastoral da Terra. 2015. Ministério Público do Trabalho no Amazonas sedia seminário sobre enfrentamento ao Trabalho Escravo. Disponível em: https://www.cptnacional.org.br/. Acesso em: 1o out 2019. 
DUSEK, Patrícia Maria. Os impactos da transmutação do vértice no direito privado: a valorização do princípio da dignidade da pessoa humana como escopo da constitucionalização do direito na era contemporânea. Amazon's Research and Environmental Law, Rondônia, v. 3, n. 1, p. 6-21, 2015.

FAUSTO, Boris. História do Brasil. 14. ed. São Paulo: Edusp, 2012.

HADDAD, Carlos Henrique Borlido. 2013. Aspectos penais do trabalho escravo. Disponível em: http://media.wix.com/ ugd/830053_bd0152c3ff1a4dcf8a9d78b9fcc832cf.pdf. Acesso em: 8 jul. 2020.

LACERDA, Clara; TOSTES, Laura Ferreira Diamantino; CANTELLI, Paula Oliveira. Um olhar contemporâneo do trabalho escravo: a luta continua. In: MIRAGLIA, L. M. M. Trabalho escravo contemporâneo. Conceituação à luz do princípio da dignidade da pessoa humana. 2. ed. São Paulo: LTR, 2018.

LAPORTA, Taís. Decreto sobre trabalho escravo no Brasil pode levar a "retrocessos lamentáveis", diz OIT. G1, 19 out. 2017. Disponível em: https://g1.globo.com/economia/noticia/decreto-sobre-trabalho-escravo-no-brasil-pode-levar-a-retrocessos-lamentaveis-diz-oit.ghtml. Acesso em: 10 jul. 2019.

MEDEIROS, Benizete Ramos. Trabalho com dignidade: educação e qualificação é um caminho? São Paulo: LTR, 2008.

MIRABETE, Julio Fabbrini. Manual de direito penal. 23. ed. São Paulo: Atlas, 2005.

MIRAGLIA, Lívia Mendes Moreira. Trabalho escravo contemporâneo. Conceituação à luz do princípio da dignidade da pessoa humana. 2. ed. São Paulo: LTR, 2015.

MIRAGLIA, Lívia Mendes Moreira; SOUZA, Adriana Augusta de Moura; CHAVES JR., José Eduardo de Resende. Trabalho escravo contemporâneo. Desafios e perspectivas. São Paulo: LTR, 2018.

MPT. Ministério Público do Trabalho. 2014. Operação conjunta de MPF e MPT resgata 13 trabalhadores. Disponível em: https://mpt.jusbrasil.com.br/. Acesso em: 10 out. 2019.

OLIVEIRA, Matheus Requião Silva. Leis abolicionistas: a história da abolição da escravatura no Brasil. 2017. In: BRASIL. Ministério Público Federal. Escravidão contemporânea. 2. Câmara de Coordenação e Revisão Criminal. Brasília: MPF, 2017.

PENHA, João Paulo. O direito à educação para o trabalho digno no contexto econômico neoliberal. 2016. Dissertação (Mestrado em Ciência Jurídica) - Universidade Estadual do Norte do Paraná, Jacarezinho, 2016.

PRADO JR., Caio. Evolução política do Brasil. São Paulo: Editora Companhia das Letras, 2012.

PRAM. Procuradoria da República no Amazonas. MPF/AM denuncia à Justiça empresário de Barcelos (AM) por trabalho escravo. 2014. Disponível em: https://pr-am.jusbrasil.com.br/noticias/157931851/mpf-am-denuncia-a-justica-empresario-de-barcelos-am-por-trabalho-escravo. Acesso em: 7 jul. 2020.

SARLET, Ingo Wolfgang. Dignidade da pessoa humana e direitos fundamentais na Constituição Federal de 1988. 10. ed. Porto Alegre: Livraria do Advogado, 2015.

SILVA, Ivone Maria Ferreira; BOAVENTURA, Bruno J.R. O trabalho escravo como expressão latente da questão social. Revista Direito Mackenzie, São Paulo, v. 6, n. 2, p. 124-139, 2014.

SUZUKI, Natália Sayuri. Políticas públicas: a relação de representação entre o estado e o trabalhador vítima de trabalho escravo. In: BRASIL. Ministério Público Federal. Escravidão contemporânea. 2a Câmara de Coordenação e Revisão Criminal. Brasília: MPF, 2017.

ZUARDI, Júlia do Rosário; RAMOS-FILHO, Carlos Alberto de Moraes; BENTES, Dorinethe dos Santos. O trabalho escravo contemporâneo: uma análise do caso trabalhadores da Fazenda Brasil Verde versus Brasil e da escravidão na Região Norte do Brasil. Revista do Tribunal Superior do Trabalho, São Paulo, v. 85, n. 2, p. 116-129, 2019. 